\title{
ТЕОРИЯ И ПРАКТИКА
}

ГОСУДАРСТВЕННО-ПРАВОВОГО РАЗВИТИЯ

DOI: https://doi.org/10.15688/lc.jvolsu.2021.3.10

UDC 340.134

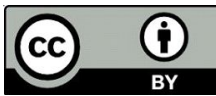

LBC 67.0

Submitted: 20.05.2021

Accepted: 14.06.2021

\section{“BIG CHALLENGES" AS A FACTOR OF TRANSFORMATION OF STATE-LEGAL RELATIONS ${ }^{1}$}

\author{
Danil V. Kononenko \\ Volgograd State University, Volgograd, Russian Federation
}

\begin{abstract}
Introduction: in recent years the "big challenges" category has rapidly come into language use. From the word combination of a prognostic-journalistic nature, the expression has penetrated normative legal acts, becoming a legal category that can potentially change social relations. However, in legal acts and a fairly small catalog of legal scientific publications, this construct is considered through the prism of socio-economic relations; its legal essence and possible state-legal transformations that may follow it are not highlighted. Purpose: to give an overview of the "big challenges" category through its genesis, transformation, and through the prism of legal realities. Methods: the methodological framework for the study was made up of general scientific methods - analysis and synthesis, as well as specific scientific methods - formal-legal and comparative-legal. Results: big challenges, initially referring to the category of scientific knowledge of the IT sphere, are subsequently used concerning a wide group of public relations, finding their consolidation in the program documents of an international and national nature. At the domestic level, acts are not only a declaration of intent but also a mandatory work plan for public authorities. In Russia, the final consolidation of the term "big challenges" in public-legal rhetoric took place in 2016, which led to the introduction of changes or the appearance of new legal acts of a planned nature. Conclusions: despite the legal definition of "big challenges" in the Strategy of Scientific and Technological Development of the Russian Federation, there is still no legal description of the institution under consideration, although it carries huge legal potential, including in the field of public administration, laying the foundations for such a promising way of influencing social relations as smart regulation. An attempt is made to define "big challenges" in the legal discourse.

Key words: big challenges, strategy, smart regulation, digitalization, transformation.
\end{abstract}

Citation. Kononenko D.V. "Big Challenges"As a Factor of Transformation of State-Legal Relations. Legal Concept = Pravovaya paradigma, 2021, vol. 20, no.3, pp. 58-65. (in Russian). DOI:https://doi.org/10.15688/lc.jvolsu.2021.3.10

УДК 340.134

Дата поступления статьи: 20.05.2021

ББК 67.0

Дата принятия статьи: 14.06.2021

«БОЛЬШИЕ ВЫЗОВЫ» КАК ФАКТОР ТРАНСФОРМАЦИИ ГОСУДАРСТВЕННО-ПРАВОВЫХ ОТНОШЕНИЙ ${ }^{1}$

\author{
Данил Валерьевич Кононенко \\ Волгоградский государственный университет, г. Волгоград, Российская Федерация \\ Введение: последние годы отмечены стремительным вторжением в языковой оборот категории «большие \\ вызовы». Из словосочетания прогностическо-публицистического плана выражение проникло в нормативные
}


Д.В. Кононенко. «Большие вызовы» как фактор трансформации государственно-правовых отношений

правовые акты, став юридической категорией, потенциально способной изменить социальные отношения. Однако в правовых актах и достаточно небольшом каталоге юридических научных публикаций данный конструкт рассматривается через призму социально-экономических отношений, не выделяются его правовая суть и возможные государственно-правовые преобразования, которые могут за ним воспоследовать. Цель: дать обзорную характеристику категории «большие вызовы» сквозь ее генезис, преобразование и через призму правовых реалий. Методы: методологическую основу исследования составили общенаучные методы - анализ и синтез, а также частнонаучные - формально-юридический и сравнительно-правовой. Результаты: «большие вызовы», изначально относясь к категории научного знания IT-сферы, впоследствии используются применительно к широким группам общественных отношений, находя свое закрепление в программных документах международного и национального характера. На внутригосударственном уровне акты являются не только декларацией намерений, но и обязательным планом работы для публичных органов управления. В России окончательное закрепление в публично-правовой риторике термина «большие вызовы» произошло в 2016 г., что привело к внесению изменений или появлению новых правовых актов планового характера. Выводы: несмотря на легальное определение «больших вызовов» в Стратегии научно-технологического развития Российской Федерации, по-прежнему отсутствует правовая характеристика рассматриваемой институции, несмотря на то что она несет в себе колоссальный правопреобразующий потенциал, в том числе и в сфере публичного управления, закладывая основы для такого перспективного способа воздействия на социальные отношения, как «smart regulation». Предпринята попытка дать дефиницию «больших вызовов» в правовом дискурсе.

Ключевые слова: большие вызовы, стратегия, умное регулирование, цифровизация, трансформация.

Цитиров ание. Кононенко Д. В. «Большие вызовы» как фактор трансформации государственноправовых отношений // Legal Concept = Правовая парадигма. - 2021. - Т. 20, № 3. - C. 58-65. - DOI: https://doi.org/10.15688/lc.jvolsu.2021.3.10

\section{Введение}

Во второй половине 2010-х гг. в русской языковой среде (наука, публицистика) закрепилось такое понятие, как «большие вызовы». Неопределенный характер громко звучащей словесной конструкции приобретает правовое наполнение в силу стремлений отечественного правотворца включать эту категорию в нормативные правовые акты. При этом «большие вызовы» и смежный с ними лингвистический аппарат оказывают существенное воздействие на последующее нормотворчество, как правило, подзаконное, но, учитывая, что речь идет о развитии положений программного свойства, влияющих на социальные отношения в перспективной хронологии, степень их важности стоит вровень с законотворчеством.

\section{Генезис категории «большие вызовы»: зарубежный и международный опыты}

В зарубежной науке такое понятие используется по меньшей мере 30 лет, изначально относясь к сфере высоких технологий [23]. Практически одновременно искомая категория появилась в лексике национальных правительственных организаций $[13 ; 26]$.
Впоследствии постановка «больших вызовов» стала использоваться и в иных сферах научного знания, а также в международной и общественной деятельности при декларировании актуальной повестки $[19 ; 21]$. Символичным актом в канун XXI столетия был доклад Генерального секретаря ООН [28], зафиксировавший постановку на общемировом уровне Целей развития тысячелетия (всего 8) как ответ на глобальные вызовы. Достижение данных целей было запланировано к 2015 г., впоследствии они были переформатированы на Цели устойчивого развития (всего 17).

Нельзя не отметить, что озвученные «большие (глобальные) вызовы» затрагивают все человечество, предполагая, что каждый субъект социальных отношений сможет включиться на своем участке в решение проблем общемирового масштаба, поскольку промедление в данной ситуации может отразиться на жизни не только последующих поколений, но и нынешнего. Несмотря на это, решающая роль в существующем формате мироустройства отводится национально-государственным и международным институциям как структурам, способным системно организовать работу большинства социальных субъектов, исходя из самого обширного перечня пол- 


\section{ТЕОРИЯ И ПРАКТИКА ГОСУДАРСТВЕННО-ПРАВОВОГО РАЗВИТИЯ}

номочий, закрепленных в международных документах и национальных нормативных правовых актах, конституирующих текущий правовой статус этих акторов. В силу принимаемых декларативных решений происходит переформатирование государственно-правовой реальности стран, присоединяющихся к инициативам по ответу на предъявленные вызовы. Вместе с тем практика реагирования может существенным образом отличаться даже в рамках государств одной правовой семьи. В США процедура ответа на «большие вызовы» имеет децентрализованный характер и сопровождается распределением роли оператора ответа на существующие проблемы между государственными и частными субъектами. Это может быть проект DARPA Grand challenge, курируемый Министерством обороны США - спортивные соревнования робототехнических устройств с целью развития транспортных средств, управляемых без непосредственного участия человека [18]. При этом в названии используется слово challenge в еще одном часто используемом значении «спортивное соревнование» [16]. Целый перечень глобальных инициатив как ответ на «большие вызовы», поддерживаемый правительственным Агентством США по международному сотрудничеству (USAID) [27]. Инициатива Grand Challenges In Global Health, провозглашенная в 2003 г., курируется крупным частным некоммерческим Фондом Билла и Мелинды Гейтс [15]. В свою очередь, в Великобритании позиционирование «больших вызовов» в правовом поле носит более централизованный характер, хотя остается на ведомственном подзаконном уровне (программа Industrial Strategy, оператор - Минестерство бизнеса, энергетики и промышленной стратегии) [20].

Подзаконный, а зачастую и декларативный характер «больших вызовов» несет в себе риски включать в содержание данного термина краткосрочные трендовые проблемы с неясной перспективой, тем самым добавляя популизма и размывая существующий термин или вычленяя частные элементы из более общих проблем. Это характерно для ситуации 2020-2021 гг. в связи с пандемией COVID-19, вплоть до использования термина «вызов» (challenge) в качестве маркетингового хода для привлечения клиентов юридических услуг [17] либо закрепляя в коммуникационной среде термин «ответ» (response) [25], предполагающий собой реагирование на «вызов» (challenge).

\section{«Большие вызовы» \\ в российском правовом поле}

Генезис правовой категории «большие вызовы» как стартовой точки связан со Стратегией научно-технологического развития Российской Федерации, утвержденной Указом Президента РФ от 01.12.2016 (далее - Стратегия) [8] и обозначенной на состоявшемся в ту же дату Послании главы государства Федеральному собранию [6].

Первые две декады 2000-х гг. ознаменовали собой появление документов смежного характера: с одной стороны, данные акты государственно-правового творчества носят в себе потенциал нормативно-правового измерения, будучи обязательными к выполнению в случае делегирования определенных полномочий, а также нахождения в определенной иерархичной системе российского правового корпуса. С другой стороны, документы подобного рода характеризуются программными, плановыми свойствами, декларированием ожидаемых достижений. Представляется, что подготовление таких актов придает планированию более строгий и обязательный к выполнению характер. Это оказывает проспективное влияние как на общественные отношения, которые являются предметом документа, так и на последующий каталог нормативных правовых актов, в том числе и законов.

Нормативно-правовая фиксация появления такого рода документов произошла в Федеральном законе от 28.06.2014 № 172-Ф3 «О стратегическом планировании в Российской Федерации» [11]. Данные акты носят не только нормативно-правовое значение, но и программно-политическое, декларируя намерения государства в той или иной сфере, «в документах планирования политические аспекты всегда излагаются в юридическом преломлении» [5, с. 488-489].

Документы стратегического планирования разрабатываются на трех уровнях: феде- 
ральном, региональном и муниципальном. В силу тематики данной статьи требуется перечисление документов федерального уровня. В рамках классификации по простейшему критерию, форме представления, таковыми являются: 1) Послание Президента; 2) стратегия; 3) доктрина; 4) основы государственной политики; 5) прогноз, 6) государственная программа; 7) основные направления деятельности; 8) схема; 9) план деятельности. При этом «большие вызовы» продекларированы в акте, относящемся к типу «стратегия», являющимся, с точки зрения законодателя, документом целеполагания, что подчеркивает особую важность выявленных проблем и путей решения. Исследователями отмечается, что стратегия - это «план действий по решению масштабной общественной проблемы... Стратегия, в отличие от доктрины, имеет намного больший размах» [4, с. 60]. Симптоматично, что для решения проблем (вне зависимости от степени их важности) требуется постановка и конституирование существующих проблем. В конечном итоге именно осознание существующих коллизий и их негативного влияния на общественные отношения позволяет выработать целеполагающие способы воздействия и нивелирования проблемного поля, не делая программный документ еще одним движением ради движения.

Самой Стратегией «большой вызов» определяется как «объективно требующая реакции со стороны государства совокупность проблем, угроз и возможностей, сложность и масштаб которых таковы, что они не могут быть решены, устранены или реализованы исключительно за счет увеличения ресурсов» (подпункт «б» пункт 4 Стратегии). Предполагается, что решение проблем, обозначенных в соответствующей Стратегии, невозможно лишь экстенсивным путем, необходима коренная перестройка общественных отношений и правовая регуляция - лишь одно из средств.

Стоит отметить, что присутствие термина «большие вызовы» (в первую очередь в информационно-технологической сфере) не воспрепятствовало тому, что в течение 2016 г. разработка этой и смежных с ней категорий осуществлялась в социально-экономическом русле. Провозвестниками правового закреп- ления «больших вызовов» в правовой среде стали: 1) панельная сессия «Большие вызовы - стимул для развития науки» Петербургского международного экономического форума, который состоялся 16.06.2016 [1], 2) работа тематической группы по разработке Стратегии при Высшей школе экономики [12]. В частности, в программе панельной сессии ПМЭФ «большие вызовы» обозначались как «комплекс проблем, рисков, возможностей, значимых факторов и долгосрочных процессов», тогда как в докладе ВШЭ «Целевое будущее России: научно-технический аспект» под «большими вызовами» понимаются «явление и методический подход в государственной социально-экономической и научной политике» и в то же время «проблемы, которые стояли перед обществом», позволяющие обеспечить единство науки, технологии и инновации (Science, technology and innovation; STI) [24]. Отмечается, что в контексте разработки социально-экономического определения «больших вызовов» российские исследователи опирались на известную формулу, использованную в различных правовых актах и отчетах правительственых служб США: «Большая (фундаментальная) проблема, решение которой требует серьезных ресурсов (инновационных подходов) и т. д.» [21].

Вследствие принятия целеполагающего стратегического документа, которым задается тон дальнейшего преобразования социальных отношений, отмечается увеличение количества иных актов стратегического свойства, развивающего исследуемую Стратегию. К примеру, большой вызов, касающийся освоения территории Арктики, получил развитие в Стратегии развития Арктической зоны Российской Федерации и обеспечения национальной безопасности на период до 2035 г. (утв. Указом Президента РФ от 26.10.2020 № 645) [10]. В то же время развитие цифровой экономики и стремление российского государства не остаться за бортом общественных изменений были уточнены в Национальной стратегии развития искусственного интеллекта на период до 2030 г. (утв. Указом Президента РФ от 10.10.2019 № 490) [9]. Иные субъекты нормотворчества также для развития положений Стратегии могут принимать акты, привносящие сущностное напол- 


\section{ТЕОРИЯ И ПРАКТИКА ГОСУДАРСТВЕННО-ПРАВОВОГО РАЗВИТИЯ}

нение и позволяющие спланировать конкретные мероприятия, решающие задачи Стратегии, к примеру, Программа фундаментальных научных исследований в Российской Федерации на долгосрочный период (20212030 гг.) (утв. Распоряжением Правительства РФ от 31.12.2020 № 3684-p) [7].

При этом, помимо классических методов регулирования со стороны государства, социум все больше и больше предъявляет запрос на иные формы и способы регулирования, поскольку «в условиях цифровизации правовой реальности имеет место процесс трансформации правовой политики» [2, с. 22]. В силу этого учеными разрабатывается концепция «умное регулирование» («smart regulation») [3], позволяющая внедрить публичные практики, адекватные ответам на возникающие «большие вызовы». Программные документы зарубежных государств уже включают в себя руководства по умному регулированию общественных процессов [14].

\section{Выводы}

«Большие вызовы» представляют собой фундаментальные проблемы и угрозы, которые могут привести к катастрофическим последствиям в общемировом масштабе. Они требуют нетривиальных решений, в том числе и в контексте государственно-правовой сферы.

«Большие вызовы» с правовой точки зрения представляют собой структурные единицы целеполагающих правовых документов стратегического планирования, фиксирующие в правовом контексте проблемное поле общегосударственного масштаба, инициирующие иерархичную систему общих, отраслевых и ведомственных документов стратегического планирования, а также изменения процедуры публично-правового управления.

\section{ПРИМЕЧАНИЕ}

${ }^{1}$ Исследование выполнено за счет средств гранта Российского научного фонда № 21-18-00484, https://rscf.ru/project/21-18-00484/.

The research was carried out at the expense of the Russian Science Foundation grant No. 21-1800484, https://rscf.ru/project/21-18-00484/.

\section{СПИСОК ЛИТЕРАТУРЫ}

1. «Большие вызовы» - стимул для развития науки // Программа панельной сессии ПМЭФ-2016. Электрон. текстовые дан. - Режим доступа: http:// youngscience.gov.ru/media/files/file/kMS9X6hbigAy TDwbALxFWfMGNABr7OYM.pdf(дата обращения: 14.05.2021). - Загл. с экрана.

2. Гаврилова, Ю. А. Трансформация правовой политики в условиях цифровизации правовой реальности / Ю. А. Гаврилова, О. С. Рыбакова // Legal Concept = Правовая парадигма. -2020 . T. 19, № 4. - C. 17-23. - DOI: https://doi.org/10.15688/ lc.jvolsu.2020.4.2.

3. Давыдова, М. Л. «Умное регулирование» как основа совершенствования современного правотворчества / М. Л. Давыдова // Журнал российского права. - 2020. - № 11. - C. 14-29. - DOI: https://doi.org/10.12737/jr1.2020.130.

4. Кононов, Л. А. Роль официальных документов: концепций, доктрин и стратегий в политическом управлении Российской Федерации / Л. А. Кононов // Право и современные государства. - 2017. № 2. - С. 55-66.

5. Мушинский, М. А. Стратегии, концепции, доктрины в правовой системе российской федерации: проблемы статуса, юридической техники и соотношения друг с другом / М. А. Мушинский // Юридическая техника. - 2018. - № 9. - С. 488-499.

6. Послание Президента РФ Федеральному Собранию от 01.12.2016 «Послание Президента Российской Федерации Федеральному Собранию» // «Парламентская газета». - 2016. - № 45.

7. Распоряжение Правительства РФ от 31.12.2020 № 3684-р «Об утверждении Программы фундаментальных научных исследований в Российской Федерации на долгосрочный период (20212030 гг.)» // Доступ из справ.-правовой системы «КонсультантПлюс».

8. Указ Президента РФ от 01.12.2016 № 642 (ред. от 15.03.2021) «О Стратегии научно-технологического развития Российской Федерации» // Доступ из справ.-правовой системы «КонсультантПлюс».

9. Указ Президента РФ от 10.10.2019 № 490 «О развитии искусственного интеллекта в Российской Федерации» (вместе с «Национальной стратегией развития искусственного интеллекта на период до 2030 г.») // Доступ из справ.-правовой системы «КонсультантПлюс».

10. Указ Президента РФ от 26.10.2020 № 645 «О Стратегии развития Арктической зоны Российской Федерации и обеспечения национальной безопасности на период до 2035 г.» // Доступ из справ.правовой системы «КонсультантПлюс».

11. Федеральный закон от 28.06.2014 № 172-Ф3 (ред. от 31.07.2020) «О стратегическом планирова- 
Д.В. Кононенко. «Большие вызовы» как фактор трансформации государственно-правовых отношений

нии в Российской Федерации» // Доступ из справ.правовой системы «КонсультантПлюс».

12. Целевое будущее России: научно-технологический аспект // Министерство образования и науки Российской Федерации, Национальный исследовательский университет «Высшая школа экономики». - Электрон. текстовые дан. - Режим доступа: https://issek.hse.ru/data/2016/06/29/1115937313/ 01_Salihov.pdf(дата обращения: 14.05.2021)._-Загл. с экрана.

13. A Research and Development Strategy for High Performance Computing. - Electronic text data. Mode of access: https:/gordonbell.azurewebsites.net/ CGB\%20Files/FCCSET\%20Research\%20and\%2 0Development $\% 20$ Strategy\%20for\%20High\%20Perf $\% 20$ Com $\% 20871120 \% 20$ c.pdf (date of access: 14.05.2021). - Title from screen.

14. A Strategy for American Innovation // National Economic Council and Office of Science and Technology Police. -2015 . $-117 \mathrm{p}$.

15. Bill and Melinda Gates Foundation. Electronic text data. - Mode of access: https:// www.gatesfoundation.org/our-work (date of access: 14.05.2021). - Title from screen.

16. Challenge // Cambridge Dictionary. Electronic text data. - Mode of access: https:// dictionary.cambridge.org/dictionary/english/challenge (date of access: 14.05.2021). - Title from screen.

17. COVID-19: Navigating the Legal Challenges. Electronic text data. - Mode of access: https:// www.stewartslaw.com/covid-19-legal-challenges/ (date of access: 14.05.2021). - Title from screen.

18. Defense Advanced Research Projects Agency. The Grand Challenge. - Electronic text data. Mode of access: https://www.darpa.mil/about-us/ timeline/-grand-challenge-for-autonomous-vehicles (date of access: 14.05.2021). - Title from screen.

19. Grand Challenges in Global Health / H. Varmus [et al.] // Science. - 2003. - P. 398-399.

20. Industrial Strategy. Building a Britain Fit for the Future. - Electronic text data. - Mode of access: https://assets.publishing.service.gov.uk/government/ uploads/system/uploads/attachment_data/file/664563/ industrial-strategy-white-paper-web-ready-version.pdf (date of access: 14.05.2021). - Title from screen.

21. Kaldewey, D. The Grand Challenges Discourse: Transforming Identity Work in Science and Science Policy / D. Kaldewey // Minerva. - 2018. Vol. 56 (2). - P. 161-182. -DOI: https://doi.org/10.1007/ s11024-017-9332-2.

22. Reddy, R. Foundations and Grand Challenges of Artificial Intelligence: AAAI Presidential Address / R. Reddy// AI Magazine. - 1988. - Vol. 9 (4). - P. 9. DOI: https://doi.org/10.1609/aimag.v9i4.950.

23. Science, Technology and Innovation (STI) and Culture for Sustainable Development and the
MDGs. - Electronic text data. - Mode of access: https://www.un.org/ecosoc/en/content/sciencetechnology-and-innovation-sti-and-culturesustainable-development-and-mdgs (date of access: 14.05.2021). - Title from screen.

24. The COVID-19 Database of Laws. - Electronic text data. - Mode of access: https:/covidlawlab.org/ (date of access: 14.05.2021). - Title from screen.

25. The National Challenge in Computer Science and Technology // The National Academies Press. Electronic text data. - Mode of access: https:// www.nap.edu/read/19119/chapter/1 (date of access: 14.05.2021). - Title from screen.

26. United States Agency for International Development. Grand Challenges for Development. Electronic text data. - Mode of access: https:// www.usaid.gov/grandchallenges (date of access: 14.05.2021). - Title from screen.

27. We The Peoples. The Role of the United Nations in the $21^{\text {st }}$ Century (Millennium Report of the Secretary-General). - Electronic text data. - Mode of access: https://www.un.org/en/events/pastevents/ pdfs/We_The_Peoples.pdf (date of access: 14.05.2021). - Title from screen.

28. Wilson, K. G. Grand Challenges to Computational Science / K. G. Wilson // Future Generation Computer Systems. - 1989. - Vol. 5, iss. 2-3. - P. 171-189. DOI: https://doi.org/10.1016/0167-739X(89)90038-1.

\section{REFERENCES}

1. «Bol'shie vyzovy» - stimul dlja razvitija nauki ["Big Challenges" are a Stimulus for the Development of Science]. Programma panel'noj sessii PMJeF-2016 [SPIEF 2016 Panel Session Program]. URL: http:// youngscience.gov.ru/media/files/file/kMS9X6hbig AyTDwbALxFWfMGNABr7OYM.pdf (accessed 14 May2021).

2. Gavrilova Ju.A., Rybakova O.S. Transformacija pravovoj politiki v uslovijah cifrovizacii pravovoj real'nosti [The Transformation of Legal Policy in the Context of Digitalization of the Legal Reality]. Legal Concept $=$ Pravovaja paradigma, 2020, vol.19, no. 4, pp. 17-23. DOI: https://doi.org/ 10.15688/lc.jvolsu.2020.4.2.

3. Davydova M.L. «Umnoe regulirovanie» kak osnova sovershenstvovanija sovremennogo pravotvorchestva ["Smart Regulation" As the Basis for Improving Modern Law-Making]. Zhurnal rossijskogo prava [Journal of Russian Law], 2020, no. 11, pp. 14-29. DOI: https://doi.org/10.12737/ jrl.2020.130.

4. Kononov L.A. Rol' oficial'nyh dokumentov: koncepcij, doktrin i strategij v politicheskom upravlenii Rossijskoj Federacii [The Role of Official Documents 
in the Political Administration of the Russian Federation (Concepts, Doctrines and Strategies)]. Pravo i sovremennye gosudarstva [Law and Modern States], 2017, no. 2. 60 p.

5. Mushinskij M.A. Strategii, koncepcii, doktriny v pravovoj sisteme rossijskoj federacii: problemy statusa, juridicheskoj tehniki i sootnoshenija drug s drugom [Strategies, Concepts, Doctrines in the Legal System of the Russian Federation: Problems of Status, Legal Technique and Correlation with Each Other]. Juridicheskaya tekhnika [Juridical Techniques], 2018, no. 9, pp. 488-499.

6. Poslanie Prezidenta RF Federal'nomu Sobraniju ot 01.12.2016 «Poslanie Prezidenta Rossijskoj Federacii Federal'nomu Sobraniju» [Presidential Address to the Federal Assembly Dated December 1, 2016]. Parlamentskaja gazeta [Parliamentary Newspaper], 2016, no. 45.

7. Rasporjazhenie Pravitel'stva RF ot 31.12 .2020 № 3684-r «Ob utverzhdenii Programmy fundamental'nyh nauchnyh issledovanij v Rossijskoj Federacii na dolgosrochnyj period (2021-2030 gg.)» [Order of the Government of the Russian Federation No. 3684-r Dated December 31, 2020 "On the approval of the Program of fundamental scientific research in the Russian Federation for the long term (2021-2030)"']. Access from Reference Legal System "KonsultantPlyus”.

8. Ukaz Prezidenta RF ot 01.12.2016 № 642 (red. ot 15.03.2021) «O Strategii nauchnotehnologicheskogo razvitija Rossijskoj Federacii» [Decree of the President of the Russian Federation No. 642 Dated December 1, 2016 "On the Strategy of Scientific and Technological Development of the Russian Federation"]. Access from Reference Legal System "KonsultantPlyus".

9. Ukaz Prezidenta RF ot 10.10.2019 № 490 «O razvitii iskusstvennogo intellekta v Rossijskoj Federacii» (vmeste s «Nacional'noj strategiej razvitija iskusstvennogo intellekta na period do 2030 g.») [Decree of the President of the Russian Federation No. 490 Dated October 10, 2019 “'On the Development of Artificial Intelligence in the Russian Federation (National strategy for the development of artificial intelligence for the period up to 2030")]. Access from Reference Legal System “KonsultantPlyus”.

10. Ukaz Prezidenta RF ot 26.10.2020 № 645 «O Strategii razvitija Arkticheskoj zony Rossijskoj Federacii i obespechenija nacional'noj bezopasnosti na period do 2035 g.» [Decree of the President of the Russian Federation No. 645 Dated October 26, 2020 "On the Strategy for the Development of the Arctic Zone of the Russian Federation and Ensuring National Security for the Period up to 2035"]. Access from Reference Legal System "KonsultantPlyus".

11. Federal'nyj zakon ot 28.06.2014 № 172-FZ (red. ot 31.07 .2020$) \ll \mathrm{O}$ strategicheskom planirovanii v
Rossijskoj Federacii» [Federal Kaw No. 172-FZ Dated June 25, 2014 "Strategic Planning in the Russian Federation"]. Access from Reference Legal System "KonsultantPlyus".

12. Celevoe budushhee Rossii: nauchnotehnologicheskij aspekt: doklad, soderzhashhij analiticheskie materialy tematicheskoj rabochej gruppy po razrabotke Strategii nauchnotehnologicheskogo razvitija RF na dolgosrochnyj period [Target Future of Russia: Scientific and Technological Aspect]. Ministerstvo obrazovaniya $i$ nauki Rossijskoj Federacii, Nacional'nyj issledovatel'skij universitet "Vysshaya shkola ekonomiki» [Ministry of Education and Science of the Russian Federation, National Research University "Higher School of Economics"]. URL: https://issek.hse.ru/data/2016/06/29/1115937313/ 01_Salihov.pdf(accessed 14 May 2021).

13. A Research and Development Strategy for High Performance Computing. URL: https:// gordonbell.azurewebsites.net/CGB\%20Files/ FCCSET\%20Research\%20and\%20Development $\% 20$ Strategy $\% 20$ for $\% 20 \mathrm{High} \% 20 \mathrm{Perf} \% 20$ Com\%20871120\%20c.pdf(accessed 14 May 2021).

14. A Strategy for American Innovation. National Economic Council and Office of Science and Technology Police, 2015. 117 p.

15. Bill and Melinda Gates Foundation. URL: https://www.gatesfoundation.org/our-work (accessed 14 May 2021).

16. Challenge. Cambridge Dictionary. URL: https:/dictionary.cambridge.org/dictionary/english/ challenge (accessed 14 May 2021).

17. COVID-19: Navigating the Legal Challenges. URL: https://www.stewartslaw.com/ covid-19-legal-challenges/ (accessed 14 May 2021).

18. Defense Advanced Research Projects Agency. The Grand Challenge. URL: https://www.darpa.mil/ about-us/timeline/-grand-challenge-for-autonomousvehicles (accessed 14 May 2021).

19. Varmus H., Klausner R., Zerhouni E., Acharya T., Daar A.S., Singer P.A. Grand Challenges in Global Health. Science, 2003, pp. 398-399.

20. Industrial Strategy. Building a Britain Fit for the Future. URL: https://assets.publishing. service.gov.uk/government/uploads/system/ uploads/attachment_data/file/664563/industrialstrategy-white-paper-web-ready-version.pdf (accessed14 May 2021).

21. Kaldewey D. The Grand Challenges Discourse: Transforming Identity Work in Science and Science Policy. Minerva, 2018, vol. 56 (2), pp. 161-182. DOI: https://doi.org/10.1007/s11024017-9332-2.

22. Reddy R. Foundations and Grand Challenges of Artificial Intelligence: AAAI Presidential Address. 
Д.В. Кононенко. «Большие вызовы» как фактор трансформации государственно-правовых отношений

AI Magazine, 1988, vol. 9 (4). 9 p. DOI: https://doi.org/ 10.1609/aimag.v9i4.950.

23. Science, Technology and Innovation (STI) and Culture for Sustainable Development and the MDGs. URL: https://www.un.org/ecosoc/en/content/sciencetechnology-and-innovation-sti-and-culture-sustainabledevelopment-and-mdgs (accessed 14 May 2021).

24. The COVID-19 Database of Laws. URL: https://covidlawlab.org/ (accessed 14 May 2021).

25. The National Challenge in Computer Science and Technology. The National Academies Press. URL: https://www.nap.edu/read/19119/chapter/1 (accessed 14 May 2021).
26. United States Agency for International Development. Grand Challenges for Development. URL: https://www.usaid.gov/grandchallenges (accessed 14 May 2021).

27. We The Peoples. The Role of the United Nations in the $21^{\text {st }}$ Century (Millennium Report of the Secretary-General). URL: https://www.un.org/en/ events/pastevents/pdfs/We_The_Peoples.pdf (accessed 14 May 2021).

28. Wilson K.G. Grand Challenges to Computational Science. Future Generation Computer Systems, 1989, vol. 5, iss. 2-3, pp. 171-189. DOI: https://doi.org/10.1016/0167-739X(89)90038-1.

\section{Information About the Author}

Danil V. Kononenko, Candidate of Sciences (Jurisprudence), Associate Professor, Department of Constitutional and Municipal Law, Volgograd State University, Prosp. Universitetsky, 100, 400062 Volgograd, Russian Federation, kononenko@volsu.ru, https://orcid.org/0000-0003-2518-5526

\section{Информация об авторе}

Данил Валерьевич Кононенко, кандидат юридических наук, доцент кафедры конституционного и муниципального права, Волгоградский государственный университет, просп. Университетский, 100, 400062 г. Волгоград, Российская Федерация, kononenko@volsu.ru, https://orcid.org/0000-0003-2518-5526 